\title{
Oral doxycycline for non-systemic urinary tract infections (UTIs) due to $P$. aeruginosa and other Gram negative uropathogens
}

\author{
B. A. Cunha
}

Received: 7 June 2012 / Accepted: 11 June 2012 / Published online: 6 July 2012

(C) Springer-Verlag 2012

Stamey was the first to introduce the concept of "urinary spectrum" of orally administered antibiotics to treat nonsystemic urinary tract infections (UTIs), i.e., cystitis or catheter associated bacteriuria (CAB). His concept was based on the principle that renally eliminated antibiotics are concentrated to high levels, i.e., supra-serum in urine in patients with intact renal function. Since antimicrobial susceptibility is in large part "concentration dependent," Stamey reasoned it would be possible to eradicate aerobic Gram negative uropathogens from urine if achievable urinary concentrations exceeded the minimal inhibitory concentration (MIC) of the uropathogen [1]. Clinicians have long pondered why some Gram negative uropathogens are eradicated from urine even when reported as "resistant." Stamey stressed that serum bases susceptibility testing is relevant only for pathogens in the blood. He and subsequently others showed that it was easy to eradicate "resistant" E. coli from the urine using oral penicillin based on this pharmacokinetic principle [2-4]. Oral antibiotics in particular should be viewed as having a urinary spectrum which may be different from its serum spectrum (Table 1).

Mukerji et al. and Musher et al. showed that oral tetracyclines eliminated Pseudomonas aeruginosa from the urine in most patients, i.e., $85 \%$ with intact renal function [9, 10]. Interestingly, in the Musher study, tetracycline was compared to doxycycline and minocycline. The use of doxycycline and minocycline yielded

\footnotetext{
B. A. Cunha $(\bowtie)$

Infectious Disease Division, Winthrop-University Hospital, 222 Station Plaza North (Suite \#432),

Mineola, NY 11501, USA

e-mail: bacunha@winthrop.org

B. A. Cunha

School of Medicine, State University of New York,

Stony Brook, NY, USA
}

similar results to conventional tetracycline with a slightly lower rate of eradication [10]. Their study was done in humans as opposed to an in vitro or animal study and remains the largest published study of treating Gram negative aerobic uropathogens in non-systemic UTIs orally with tetracycline, doxycycline or minocycline. Interestingly, clinical effectiveness of tetracyclines was highest with $P$. aeruginosa but was somewhat less effective against E. coli [10]. At the present time, the clinical significance of these findings is more important than ever due to the limited number of oral anti- $P$. aeruginosa antibiotics available for the treatment of Gram negative nosocomial cystitis/CAB (Table 2) [5, 14-16].

Treating nosocomial non-systemic UTIs due to aerobic Gram negative uropathogens is a common therapeutic challenge. If treatment of nosocomial cystitis/CAB due to nonfermentative Gram negative uropathogens, e.g., P. aeruginosa is desired, most clinicians resort to parenteral therapy $[5,16]$. Clinicians base antibiotic selection on serum-based susceptibility reports $[17,18]$. Few physicians would consider using oral doxycycline to treat non-systemic $P$. aeruginosa UTIs. Clinicians often forget that in vitro susceptibility testing is based on achievable serum concentrations for rapidly growing aerobic organisms and primarily pertains to bloodstream infections. In vitro susceptibility testing, by definition, is at best an extrapolation of conditions at the site of infection, i.e., with lower UTIs since susceptibility testing is performed in broth (not serum), at serum $\mathrm{pH}=7.4$ (not urinary $\mathrm{pH}$ ) and at $35{ }^{\circ} \mathrm{C}$ (not body temperature) $[19,20]$. For lower tract UTIs, some have tried to more closely predict in vivo effectiveness by performing susceptibility tests on Gram negative uropathogens in human urine, at urinary $\mathrm{pH}$, and at achievable urinary concentrations (Table 3) [21]. Performed in this manner, in vitro susceptibility results differ markedly from serum based in vitro susceptibility testing [22-24]. This best explains the 
Table 1 Urinary spectrum of oral penicillins ${ }^{\mathrm{a}}$ [5-8]

\begin{tabular}{|c|c|c|c|}
\hline Parameters & Penicillin & Ampicillin & Amoxicillin \\
\hline Oral dose & $500 \mathrm{mg}$ & $500 \mathrm{mg}$ & $500 \mathrm{mg}$ \\
\hline Serum levels & $0.5 \mathrm{mcg} / \mathrm{ml}$ & $2 \mathrm{mcg} / \mathrm{ml}$ & $4 \mathrm{mcg} / \mathrm{ml}$ \\
\hline Urine levels & $>100 \mathrm{mcg} / \mathrm{ml}$ & $>300 \mathrm{mcg} / \mathrm{ml}$ & $>600 \mathrm{mcg} / \mathrm{m}$ \\
\hline Urinary spectrum & $\begin{array}{l}\text { E. coli, } \\
\text { P. mirabilis, } \\
\text { E. faecalis } \\
\text { (VSE) }^{\mathrm{b}}\end{array}$ & $\begin{array}{l}\text { E. coli, } \\
\text { P. mirabilis, } \\
\text { E. faecalis } \\
\text { (VSE) }^{\mathrm{b}}\end{array}$ & $\begin{array}{l}\text { E. coli, } \\
\text { P. mirabilis, } \\
\text { E. faecalis } \\
\text { (VSE) }^{\mathrm{b}}\end{array}$ \\
\hline
\end{tabular}

${ }^{\text {a }}$ With normal renal function

b $\mathrm{MIC}$ 's $<8 \mathrm{mcg} / \mathrm{ml}$

frequent clinical observation that often Gram negative uropathogens are eliminated from the urine in lower tract UTIs when serum-based susceptibility testing indicated the isolate was resistant $[6,25]$. It has been shown in vitro that $64 \%$ of ampicillin resistant $E$. coli strains were susceptible when tested in human urine, at urinary $\mathrm{pH}$ and urinary concentrations (Table 4) [26].

The implications of these findings are clearly clinically important. Until susceptibility testing is based on factors relevant to the site of infection, e.g., UTIs with susceptibility performed in human urine, at urinary $\mathrm{pH}$, and at achievable urinary concentrations, infectious disease clinicians will continue to try to predict urinary susceptibilities based on the site of infection and pharmacokinetic principles, i.e., tissue concentration, $\mathrm{pH}$, etc. [6, 17, 19, 26-28]. Clinically, this problem most frequently is encountered in treating nonsystemic UTIs. As a general rule, if a Gram negative uropathogen is reported as susceptible, one may be assured the antibiotic will be effective against the organism if renal function is intact, i.e., if therapeutic urinary concentrations can be achieved. Conversely, if serum-based susceptibility of a Gram negative uropathogen is reported as resistant, the clinician needs to estimate achievable urinary concentrations taking into account renal function, the MIC of the uropathogen and the effect of urine $\mathrm{pH}$ on the activity of

Table 2 Urinary spectrum of oral tetracyclines ${ }^{\mathrm{a}}[5,6,11-13]$

\begin{tabular}{lll}
\hline Parameters & Tetracycline & Doxycycline \\
\hline Oral dose & $500 \mathrm{mg}$ & $100 \mathrm{mg}$ \\
Serum levels & $2 \mathrm{mcg} / \mathrm{ml}$ & $4 \mathrm{mcg} / \mathrm{ml}$ \\
Urine levels & $>300 \mathrm{mcg} / \mathrm{ml}$ & $>150 \mathrm{mcg} / \mathrm{ml}$ \\
Urinary spectrum & E. coli, Klebsiella sp., & E. coli, Klebsiella sp., \\
& Enterobacter sp., & Enterobacter sp., \\
& Indole + Proteus sp., & Indole + Proteus sp., \\
& Pseudomonas & Pseudomonas \\
& aeruginosa & aeruginosa \\
\end{tabular}

${ }^{\text {a }}$ With normal renal function

b MIC's $<150 \mathrm{mcg} / \mathrm{ml}$
Table 3 The effect of urinary $\mathrm{pH}$ on antibiotic activity [6]

\begin{tabular}{|c|c|}
\hline Parameter & Antibiotic \\
\hline $\begin{array}{l}\text { Optimal activity at urinary } \mathrm{pH} \\
(\mathrm{pH} \mathrm{5.5-6)}\end{array}$ & $\begin{array}{l}\text { Penicillin G } \\
\text { Trimethoprim-sulfamethoxazole } \\
\text { (TMP-SMX) } \\
\text { Oral cephalosporins }\end{array}$ \\
\hline $\begin{array}{l}\text { Activity not affected by urinary } \\
\mathrm{pH}\end{array}$ & $\begin{array}{l}\text { Ampicillin } \\
\text { Nalidixic acid/oxolinic acid } \\
\text { Chloramphenicol }\end{array}$ \\
\hline $\begin{array}{l}\text { Activity increased by acid urine } \\
(\mathrm{pH}<6)\end{array}$ & Tetracycline \\
\hline $\begin{array}{l}\text { Activity requires an acid urine } \\
(\mathrm{pH}<6)\end{array}$ & $\begin{array}{l}\text { Methenamine mandelate/ } \\
\text { methenamine hippurate }\end{array}$ \\
\hline $\begin{array}{l}\text { Activity increased by alkaline } \\
\text { urine }(\mathrm{pH}>6)\end{array}$ & $\begin{array}{l}\text { Erythromycin } \\
\text { Aminoglycosides } \\
\text { Sulfonamides } \\
\text { Nitrofurantoin }\end{array}$ \\
\hline
\end{tabular}

the antibiotic since the isolate may in fact be susceptible under these conditions [6, 22-27].

The therapeutic efficacy of an antibiotic to treat nonsystemic UTIs due to aerobic Gram negative uropathogens is dependent on intact renal function to assure therapeutic urinary concentrations $>$ MIC of the uropathogen. Further consideration is needed if the patient has renal insufficiency. For mild-moderate renal insufficiency, i.e., $\mathrm{CrCl}>50 \mathrm{ml} / \mathrm{min}$, urinary antibiotic concentrations are likely to be effective $[10$, 13]. However, if renal function is decreased by more than half, i.e., $\mathrm{CrCl}<50 \mathrm{ml} / \mathrm{min}$, then estimated achievable urinary concentrations must be halved. If the halved concentration is still > MIC of the organism, then eradication of the uropathogen from the lower urinary tract is still possible $[7,8,11,12,29]$. Depending upon the MIC of the aerobic Gram negative uropathogen, even with a creatinine clearance of $30-50 \mathrm{ml} / \mathrm{min}$, many isolates will still be eradicated by oral doxycycline therapy $[5,10,12]$. If an oral tetracycline is being used to treat $P$. aeruginosa cystitis/ $\mathrm{CAB}$ with renal insufficiency, i.e., $\mathrm{CrCl}<50 \mathrm{ml} / \mathrm{min}$, then doxycycline is preferred. If an oral penicillin or ampicillin is

Table 4 Ampicillin resistant E. coli tested in human urine at urinary $\mathrm{pH}$ and at urinary concentrations

\begin{tabular}{|c|c|c|c|c|}
\hline \multirow{2}{*}{$\begin{array}{l}\text { Oral } \\
\text { antibiotic }\end{array}$} & \multicolumn{2}{|l|}{ Broth pH 7.4} & \multicolumn{2}{|l|}{ Urine $^{\mathrm{a}} \mathrm{pH} 6.0$} \\
\hline & $\begin{array}{l}\text { \% Susceptibility } \\
(n / N)\end{array}$ & $\begin{array}{l}\text { \% Resistant } \\
(n / N)\end{array}$ & $\begin{array}{l}\text { \% Susceptibility } \\
(n / N)\end{array}$ & $\begin{array}{l}\text { \% Resistant } \\
(n / N)\end{array}$ \\
\hline Ampicillin & $0 \%(0 / 25)$ & $100 \%(25 / 25)$ & $64 \%(16 / 25)$ & $36 \%(9 / 25)$ \\
\hline Amoxicillin & $28 \%(7 / 25)$ & $72 \%(18 / 25)$ & $100 \%(25 / 25)$ & $0 \%(0 / 25)$ \\
\hline Doxycycline & $40 \%(10 / 25)$ & $60 \%(15 / 25)$ & $76 \%(19 / 25)$ & $24 \%(6 / 25)$ \\
\hline
\end{tabular}

Adapted from Ristuccia and Cunha [26]

${ }^{a}$ Human urine heat treated to remove thermolabile anti-bacterial activity 
being used to treat "resistant" $E$. coli cystitis/CAB in a patient with renal insufficiency, i.e., $\mathrm{CrCl}<50 \mathrm{ml} / \mathrm{min}$, then amoxicillin is preferred. At any given dose, oral amoxicillin achieves much higher urinary concentrations than with oral ampicillin $[5,7,8]$. Clinicians have no readily available way to approximate the urinary spectrum of orally administered (non-cephalosporin, non-quinolone) antibiotics. This information is presented in Tables 1, 2, 3, and 4.

My infectious disease training heavily emphasized the pharmacokinetic aspects of antimicrobial therapy. Based on Stamey's work, as an infectious disease fellow I began treating non-systemic UTIs due to aerobic Gram negative uropathogens with oral antibiotics. My first experiences were treating "resistant" E. coli cystitis/CAB with oral penicillin V. However, because many oral antibiotics were available to treat "resistant" $E$. coli cystitis/CAB, the real clinical challenge was in orally treating more problematic aerobic Gram negative uropathogens, e.g., Pseudomonas aeruginosa. I began using oral doxycycline to treat $P$. aeruginosa cystitis/CAB with good results, i.e., oral doxycycline eliminated $P$. aeruginosa from the urine in $\sim 75 \%$ of cases. During the past 35 years in infectious disease, I have continued to utilize this approach for $P$. aeruginosa cystitis/CAB as well as other aerobic Gram negative uropathogens causing nosocomial cystitis/CAB. In infectious disease consultation, many practitioners feel they have few therapeutic options unless an intravenous antibiotic is used. However, clinicians still ponder in disbelief when an oral antibiotic, e.g., doxycycline is used for formidable uropathogen, e.g., P. aeruginosa. Because tetracyclines are not routinely tested against Gram negative uropathogens many physicians do not even consider doxycycline a therapeutic option $[11,12,17,18,20]$. I continue to use oral antibiotics successfully based on the estimated urinary concentrations to eliminate a variety of aerobic Gram negative uropathogens from bladder urine.

Excluding cephalosporin and quinolones, currently there are few oral therapeutic alternatives to treat aerobic Gram negative uropathogens causing nosocomial cystitis/CAB $[5$, $11,15,16,30]$. Some oral antibiotics offer an effective alternative to parenteral antibiotics. In this era of limited healthcare resources, carefully selected oral antimicrobial therapy offers a cost effective alternative to intravenous (IV) therapy. Oral antibiotic therapy is less expensive in terms of acquisition and administration costs than comparable IV antibiotic therapy and patients generally prefer oral to IV antibiotics. Obviously, the use of oral antimicrobial therapy virtually eliminates the complications of phlebitis and IV line infections associated with IV antimicrobial therapy. Oral antimicrobial therapy for aerobic Gram negative uropathogens with its many advantages has some limitations [5]. First, oral antibiotic therapy is most likely efficacious using renally eliminated antibiotics in patients with intact renal function to assure high urinary concentrations $>$ the
MIC of aerobic Gram negative uropathogens [6, 19]. Second, oral antimicrobial therapy will not be effective against all strains anymore than IV antibiotic therapy will always be effective [5, 16]. Against multi-drug resistance (MDR) Gram negative uropathogens there are few oral antimicrobial options, e.g., methenamine salts for $\mathrm{CAB}$, nitrofurantoin for nosocomial cystitis/CAB or fosfomycin for nosocomial cystitis/CAB (Table 5) [5, 30-33]. Third, oral antimicrobial therapy will be less effective in renal insufficiency and may be ineffective in some patients if renal function is $<50 \mathrm{ml} / \mathrm{min}$. Tetracycline or doxycycline may be used in patients without renal insufficiency. Doxycycline is the preferred tetracycline for treating nonsystemic UTIs due to non-MDR strains of $P$. aeruginosa patients with renal insufficiency. Although doxycycline is effective against most strains of $P$. aeruginosa $(\sim 75 \%)$ in urine, doxycycline may be ineffective in $\sim 25 \%$ of strains if the MIC cannot be achieved when doxycycline levels in the urine are not $>$ MIC or if the Gram negative uropathogen is a MDR strain [1, 14].

Since urine cultures often take days to be reported, clinical effectiveness may be rapidly predicted by urinalysis (UA). If antibiotic therapy will be effective, the intensity of pyuria in the UA will decrease rapidly. Decreased pyuria is predictive of subsequent urine culture negativity before urine cultures are reported negative later. Persistent pyuria predicts therapeutic failure. If doxycycline fails, the uropathogen is a strain with a MIC $>$ than achievable urinary concentrations or is an MDR strain and fosfomycin is most likely to be effective $[32,33]$. The great majority of aerobic Gram negative uropathogens, e.g., P. aeruginosa causing non-systemic UTIs, i.e., cystitis/CAB, can be effectively treated simply and inexpensively with oral doxycycline.

Table 5 Oral antibiotic therapy of non-systemic urinary tract infections (UTIs) due to MDR Gram negative uropathogens ${ }^{\mathrm{a}}$

\begin{tabular}{|c|c|c|}
\hline Parameters & $\begin{array}{l}\text { Methenamine salts } \\
\text { (methenamine hippurate/ } \\
\text { mandelate) }\end{array}$ & Fosfomycin \\
\hline Oral dose & $100 \mathrm{mg}$ & $3 \mathrm{gm}$ \\
\hline Serum levels & Formaldehyde level $=0$ & $26 \mathrm{mcg} / \mathrm{ml}$ \\
\hline Urine levels & $\begin{array}{l}\text { Formaldehyde }>20 \mathrm{mcg} / \mathrm{ml} \\
\text { (dependent on urine } \mathrm{pH}, \\
\text { time, volume) }\end{array}$ & $1000-4000 \mathrm{mcg} / \mathrm{ml}$ \\
\hline $\begin{array}{l}\text { Urinary } \\
\text { spectrum }\end{array}$ & $\begin{array}{l}\text { E. coli, Klebsiella sp., } \\
\text { Enterobacter sp., } \\
\text { Serratia marcescens, } \\
\text { P. aeruginosa }\end{array}$ & $\begin{array}{l}\text { E. coli, } \\
\text { Klebsiella sp., } \\
\text { Enterobacter sp., } \\
\text { Serratia marcescens, } \\
\text { P. aeruginosa }\end{array}$ \\
\hline
\end{tabular}

\footnotetext{
$M D R$ multi-drug resistant

${ }^{a}$ With normal renal function

${ }^{b}$ For CAB only
} 
Conflict of interest The author declares that there is no conflict of interest.

\section{References}

1. Stamey TA, Fair WR, Timothy MM, Millar MA, Mihara G, Lowery YC (1974) Serum versus urinary antimicrobial concentrations in cure of urinary-tract infections. N Engl J Med 291:1159-1163

2. Hulbert J (1972) Gram-negative urinary infection treated with oral penicillin G. Lancet 12:1216

3. Holloway WJ (1972) The use of oral penicillins and cephalosporins in the treatment of urinary tract infections. J Clin Pharmacol 1:1-6

4. Feit RM, Fair WR (1979) The treatment of infection stones with penicillin. J Urol 122:592-594

5. Cunha BA (2012) Antibiotic essentials, 11th edn. Jones \& Bartlett, Sudbury

6. Cunha BA, Comer JB (1979) Pharmacokinetic considerations in the treatment of urinary tract infections. Conn Med 43:347-353

7. Geddes AM, Gould I (2010) Phenoxypenicillins. In: Grayson ML, Crowe SM, McCarthy JS, Mills J, Mouton JW, Norrby SR (eds) Kucers' the use of antibiotics. Hodder Arnold, London, pp 59-64

8. Geddes AM, Gould IM (2010) Ampicillin, amoxicillin and other ampicillin-like penicillins. In: Grayson ML, Crowe SM, McCarthy JS, Mills J, Mouton JW, Norrby SR (eds) Kucers' the use of antibiotics. Hodder Arnold, London, pp 65-92

9. Mukerji AC, Sharma MM, Taneja OP, Saxena SN, Bhatnagar RK, Ghosh-Ray B (1969) A clinical trial of alpha-6-deoxyoxytetracycline (doxycycline) in the treatment of urinary tract infections. Chemotherapy $14: 77-85$

10. Musher DM, Minuth JN, Thorsteinsson SB, Holmes T (1975) Effectiveness of achievable urinary concentrations of tetracyclines against "tetracycline-resistant" pathogenic bacteria. J Infect Dis 131:S40-S44

11. Eisen D (2010) Tetracycline. In: Grayson ML, Crowe SM, McCarthy JS, Mills J, Mouton JW, Norrby SR (eds) Kucers' the use of antibiotics. Hodder Arnold, London, pp 843-851

12. Eisen DP (2010) Doxycycline. In: Grayson ML, Crowe SM, McCarthy JS, Mills J, Mouton JW, Norrby SR (eds) Kucers' the use of antibiotics. Hodder Arnold, London, pp 851-869

13. Grayson ML, Crowe SM, McCarthy JS, Mills J, Mouton JW, Norrby SR, (eds) (2010) Minocycline. In: Kucers' the use of antibiotics. Hodder Arnold, London, pp 870-880

14. Cunha BA (2011) Multidrug-resistant gram-negative bacilli causing urinary tract infections: clinical considerations. J Chemother 23:171-174

15. Cunha BA, Schoch P, Hage JE (2012) Oral therapy of catheterassociated bacteriuria $(\mathrm{CAB})$ in the era of antibiotic resistance: nitrofurantoin revisited. J Chemother 24:122-124

16. Meier S, Weber R, Zbinden R, Ruef C, Hasse B (2011) Extendedspectrum $\beta$-lactamase-producing Gram-negative pathogens in community-acquired urinary tract infections: an increasing challenge for antimicrobial therapy. Infection 39:333-340
17. Doern GV, Brecher SM (2011) The clinical predictive value (or lack thereof) of the results of in vitro antimicrobial susceptibility tests. J Clin Microbiol S11-S14

18. Stamey TA (1972) Urinary infections. Williams \& Wilkins, Baltimore, pp 31-53, 253-269

19. Comer JB, Ristuccia PA, Digamon M, Cunha BA (1984) Urine. In: Ristuccia AM, Cunha BA (eds) Antimicrobial Therapy. Raven Press, New York, pp 487-488

20. Hollick GE, Washington JA (1976) Comparison of direct and standardized disk diffusion susceptibility testing of urine cultures. Antimicrob Agents Chemother 9:804-809

21. Breteler KK, Rentenaar RJ, Verkaart G, Sturm PDJ (2011) Performance and clinical significance of direct antimicrobial susceptibility testing on urine from hospitalized patients. Scand J Infect Dis 43:771-776

22. McNulty CAM, Richards J, Livermore DM, Little P, Charlett A, Freeman E, Harvey I, Thomas M (2006) Clinical relevance of laboratory-reported antibiotic resistance in acute uncomplicated urinary tract infection in primary care. J Antimicrob Chemother 58:1000-1008

23. Cunha BA (2006) The clinical significance of resistant uropathogens in ambulatory urinary tract infections in woman. Scand $J$ Infect Dis 38:235-236

24. Cunha BA, Klein NC, Hamid NS (2005) Falsely high antibiotic resistance in community-acquired E. coli UTIs requiring hospitalization. Mayo Clin Proc 80:824-828

25. Cunha BA (1997) Problems arising in antimicrobial therapy due to false susceptibility testing. J Chemother 1:25-35

26. Ristuccia PA, Cunha BA (1986) Activity of antimicrobial agents at urinary concentrations against ampicillin-resistant $\mathrm{E}$. coli in human urine. Adv Ther 3:163-167

27. Cunha BA (2012) Predicting in vivo effectiveness from in vitro susceptibility: a step closer to performing testing of uropathogens in human urine. Scand J Infect Dis 44:(in press)

28. Burd E, Kehl S (2011) A critical appraisal of the role of the clinical microbiology laboratory in the diagnosis of urinary tract infections. J Clin Microbiol 49:S34-S38

29. Frimodt-Moller N (2010) Fosfomycin. In: Grayson ML, Crowe SM, McCarthy JS, Mills J, Mouton JW, Norrby SR (eds) Kucers' the use of antibiotics. Hodder Arnold, London, pp 935-944

30. Auer S, Wonja A, Hell M (2010) Oral treatment options for ambulatory patients with urinary tract infections caused by extended-spectrum-beta-lactamase-producing Escherichia coli. Antimicrob Agents Chemother 54:4006-4008

31. Grayson ML, Whitby M (2010) Methenamine mandelate and methenamine hippurate. In: Grayson ML, Crowe SM, McCarthy JS, Mills J, Mouton JW, Norrby SR (eds) Kucers' the use of antibiotics. Hodder Arnold, London, pp 1205-1210

32. Falagas ME, Kastoris AC, Kapaskelis AM, Karageorgopoulos DE (2010) Fosfomycin for the treatment of multidrug-resistant, including extended-spectrum beta lactamase producing, Enterobacteriaceae infections: a systemacic review. Lancet Infect Dis 10:43-50

33. Michalopoulos AS, Livaditis IG, Gougoutas V (2011) The revival of fosfomycin. Int J Infect Dis 15:e732-739 